\title{
Frédérique LANGUE, Histoire du Venezuela
}

\section{Myriam Cottias}

\section{OpenEdition}

\section{Journals}

Édition électronique

URL : http://journals.openedition.org/plc/418

DOI : 10.4000/plc. 418

ISSN : 2117-5209

\section{Éditeur}

L'Harmattan

\section{Édition imprimée}

Date de publication : 1 janvier 2000

Pagination : 190-194

ISSN : 1279-8657

\section{Référence électronique}

Myriam Cottias, "Frédérique LANGUE, Histoire du Venezuela », Pouvoirs dans la Caraïbe [En ligne], 12 |

2000, mis en ligne le 04 mars 2011, consulté le 22 septembre 2020. URL : http://

journals.openedition.org/plc/418; DOI : https://doi.org/10.4000/plc.418

Ce document a été généré automatiquement le 22 septembre 2020.

(c) Pouvoirs dans la Caraïbe 


\title{
Frédérique LANGUE, Histoire du Venezuela
}

\author{
Myriam Cottias
}

\section{RÉFÉRENCE}

Frédérique LANGUE, Histoire du Venezuela. Paris : L'Harmattan, 1999.

1 C'est une somme historique d'importance sur le Venezuela que nous livre ici Frédérique Langue. Tournée vers la Caraïbe, fermant cette “Méditerranée des Caraibes" ainsi que l'historiographie se plaît à l'appeler par des référents trop occidentaux, le Venezuela est terre de paradoxes et de diversités, peu d'unité malgré une des premières grandes révolutions d'Indépendance de la modernité et des hommes politiques entourés d'une aura quasi éternelle telle que Simon Bolivar, el Libertador.

2 La “petite Venise" des Amériques, telle qu'elle est dénommée par Alonso de Ojeda, compagnon de route de Christophe Colomb, - ou bien l'origine du mot est-il indigène? - fut investie par les Espagnols dans la poursuite du rêve d'or et perles de l'Europe chrétienne à partir de 1498.

3 Voilà bien le premier des paradoxes. Les peuples amérindiens et leurs terres ne pouvaient pas l'offrir, non plus qu'un paradis terrestre. La nature tropicale était foisonnante mais difficile; l'exploitation agricole du sol, quasi impossible jusqu'au XVII ${ }^{\mathrm{e}}$ siècle.

4 Hormis la mission civilisatrice et évangélique dont l'Europe s'investît sur le long terme, l'histoire du Venezuela s'est déroulée en quatre temps : les différentes conquêtes et la fondation des villes (1498-1567) ; la domination économique du cacao (l'“ or noir ") avec l'affirmation de Caracas comme capitale régionale (1567-1810); la formation du “caractère national" et la Révolution d'Indépendance avec Bolivar (1810-1830); les avatars de l'Etat national (de 1830 à nos jours).

5 Cette étude historique exhaustive insiste sur le lien entre l'économique et le social, l'un et l'autre se façonnant mutuellement. En effet, à cause du développement du cacao, les 
encomiendas sont élaborées à partir de 1545. Fondées sur le tribut, les Indiens doivent un certain nombre de jours de travail de la terre. Cependant, petit à petit, la région va intégrer les circuits économiques transatlantiques. Le commerce du cacao fleurit créant les premiers heurts avec la Couronne espagnole et le premier sursaut autonomistes des Créoles mais surtout l'importation d'une nouvelle main d'œuvre, chacun de ces éléments modelant de façon durable la société. Des Africains y sont déportés par la traite de 1529 à 1810 pour remplacer la main d'œuvre indienne et assurer le développement économique: ils engendreront progressivement une population métisse, les pardos (majoritaire à $45 \%$ dans la Province de Caracas) qui deviendra le fleuron révolutionnaire. Des Espagnols s'y enracinent en devenant propriétaires terriens, commerçants, grands miniers: ils formeront l'élite blanche aristocratique, "Espagnols européens" quand ils viennent d'arriver, mantuanas quand ils sont "créoles" (90 \% en 1800). Il y a aussi les blancos de orilla, "petits-blancs sans fortune" (commerçants, artisans, journaliers...), sans statut social réel et " qui devront attendre les premières décennies du XIX ${ }^{e}$ siècle, soit bien après la révolution d'Indépendance, pour obtenir un semblant de reconnaissance sociale " (87).

6 Cette mosaïque de populations placées dans une forme hiérarchisée et malgré un métissage culturel souterrain, pose un des fondements de la Révolution d'Indépendance (1810-1830) qui a souvent été présentée comme une " guerre des castes et des classes". Profitant de la crise politique de l'Espagne à partir de 1808 et de l'abdication de Fernando VII en faveur de José, frère de Napoléon, annoncée par des révoltes et des conspirations comme celle de Francisco de Miranda en 1806, la Révolution est plurielle et diverse. En effet, dans le débat national, certains considèrent la Première République qui commence le 19 avril 1810, comme une jornada espanola "marquant ainsi la distance qui séparait les aspirations des protagonistes du mouvement d'émancipation - en particulier certains représentants de l'aristocratie créole - et celle émanant d'acteurs sociaux plus 'populaires"' (123). Les avatars révolutionnaires n'étaient en effet pas achevés puisque guerre civile et restauration monarchique agitent le pays entre 1810 et 1817, date de fondation de la Troisième République et de l'installation du gouvernement républicain de Bolivar à Angostura. Le mouvement culmine en 1819 par la création de la Grande Colombie formée du Venezuela, de la Nouvelle-Grenade et de l'Equateur annoncée dans le "Discours d'Angostura" pour "rejeter "le joug de l'esclavage" dont sont porteuses les ambitieuses nations européennes, établir un équilibre et mettre un terme à la prépondérance de l'Europe " (148). On le sait, le grand projet bolivarien fut un échec du fait de l'atomisation des volontés politiques émanant des nations que Simon Bolivar avait lui-même rendu indépendantes et des accusations par ses pairs de tyrannisme. En 1830, il décide de se retirer du pouvoir en concluant que "l'Indépendance est le seul bien que nous avons acquis au détriment de tous les autres" (149). La même année, la séparation des pays de la Grande Colombie est prononcée par José Antonio Paez qui exige l'expulsion de Bolivar qui meurt quelques mois plus tard, le17 décembre 1830.

7 Pourtant, le rayonnement de cette révolution fut immense tant en Europe - sur le mouvement libéral espagnol, par exemple - qu'en Amérique Latine et dans les Antilles. Frédérique Langue souligne d'ailleurs un élément primordial, à savoir comment la révolution d'indépendance a mis en jeu les réseaux caribéens. L'importance d'Haïti dans le parcours de Simon Bolivar en est un exemple puisqu'il conduisit avec l'aide haïtienne deux expéditions vers le Venezuela (136). 
8 L'état vénézuélien est consolidé le 22 septembre 1830. Il se dote d'une Constitution fondant la citoyenneté sur la " qualité d'homme libre " pour ceux qui naissaient dans le pays. On peut noter cependant que l'esclavage n'est pas aboli pour autant: la loi de manumission instaurée prévoit la libération des esclaves à partir de 21 ans et après indemnisation de leur propriétaire. La révolution n'avait pas soufflé son vent de liberté sur l'ensemble de la population! Cette constatation restreint les déclarations des révolutionnaires alors que l'époque bruissait de discours abolitionnistes et qu'Haïti était la première république noire fondée sur la libération des esclaves. Paradoxe.

C'est une ère chaotique qui s'instaure tant sur le plan politique que sur le plan économique et social à partir de 1830. Du “Centaure de l'Indépendance " à Monagas, le Venezuela passe d'un régime républicain autoritaire à une "première autocratie libérale" avec José Tadeo Monagas alors que les prix agricoles baissent, que les propriétaires et les agriculteurs sont endettés et que les exportations diminuent... Des revendications sociales en sont issues qui remettent en cause la hiérarchie raciale : les pardos organisent des révoltes dès 1843 et mettent en accusation les "Blancs". Ils réclament la répartition des terres et l'abolition de l'esclavage (175), notamment en 1846 avec le soulèvement d'Ezequiel Zamora, "général du peuple souverain ". C'est d'ailleurs dans un climat d'insurrection que le 24 mars 1854 est promulguée la loi d'abolition de l'esclavage : 12090 esclaves sont libérés, soit $2 \%$ de la population du Venezuela (187).

10 La consolidation de l'Etat n'était pas faite cependant. Le processus fut long. A partir de 1859, le pays connaît des régimes dictatoriaux rythmés par des soulèvements armés, des révoltes et des révolutions (un seul épisode démocratique entre 1936 et 1944) jusqu'à la chute de Marcos Perez Jimenez en 1958. Elle fonde la démocratie. Le Venezuela aborde le $\mathrm{XX}^{\mathrm{e}}$ siècle avec des crises de contradictions : la constitution d'une Fédération alors que le régime politique est centralisateur; des références constantes à Dieu dans les textes politiques alors que le régime est profondément laïc. Les conditions économiques sont instables, minées par des grèves tandis que les productions changent. Dès 1929, le pétrole venezuelien arrive au second rang mondial en terme de production tandis que le café décline définitivement. La nouvelle donne de la Modernité était posée. Elle va se développer sur fond de stabilité politique à partir de 1958 mettant le Venezuela en position de "modèle démocratique" tandis que le pays “décollait économiquement" sous la férule de l'Etat. Jusqu'à la crise de 1983 et les révoltes de 1989, le mythe d'un Venezuela éternellement prospère s'était développé. Le livre s'achève en exposant les désillusions sociales et politiques qui traversent le pays actuellement et les aspirations à un " renouvellement des structures participatives".

11 Le texte de Frédérique Langue est foisonnant et riche, parfois un peu trop car il rend la démonstration difficile à suivre! Le récit de l'auteur enthousiaste s'emballe souvent et souligne dans une vision historique large, échos et références à une histoire régionale. c'est donc un ouvrage indispensable qui comble une lacune historiographique. 


\section{AUTEURS}

MYRIAM COTTIAS

Membre du CRPLC

Université des Antilles et de la Guyane 